\title{
NDM arrived to Republic of Georgia
}

Authors: Koiava, T${ }^{1}$, Gonçalves, D. ${ }^{2,3}$, Palmeira, J. ${ }^{2}$, Arobelidze, K. ${ }^{4}$, Tediashvili, M. ${ }^{5}$, Akhvlediani, L. ${ }^{1}$ and H. Ferreira ${ }^{2 *}$

Affiliation:

(1) Batumi Shota Rustaveli State University, Republic of Georgia

(2) UCIBIO, Microbiology Service, Biological Sciences Department, Faculty of Pharmacy of University of Porto, Portugal

(3) Superior Health Institute of Alto Ave, Amares, Portugal

(4) National Center for Disease Control and Public Health in Adjara, Republic of Georgia

(5) Eliava Institute of Bacteriophage, Republic of Georgia

${ }^{*}$ Corresponding Author

Mailing address:

Helena Ferreira

Universidade do Porto, Faculdade de Farmácia

Rua de Jorge Viterbo Ferreira 228, 4050-313 Porto, Portugal

Phone: +351-22-042-85-80

Fax: $+351-22-042-85-90$

Email: hferr@ff.up.pt 
Sir,

Newly emerged carbapenemase New Delhi metallo- $\beta$-lactamase (NDM) type (NDM-1 to NDM-16 variants according to the gene bank available at the Lahey Clinic website (http://www.lahey.org/studies/other.asp) is an increasingly significant mechanism of resistance including the last resort $\beta$-lactams, carbapenems, with particular attention to healthcare network worldwide. This carbapenem-resistance mechanism is mostly associated to Klebsiella pneumoniae (K. pneumoniae), Escherichia coli and recently to nonfermenting Gram negatives [1, 2]. Multiple mechanisms, including the production of carbapenemases (e.g. KPC, VIM, IMP, NDM, OXA-48-like), alterations in outer membrane permeability mediated by porin loss and the upregulation of efflux systems, can contribute to carbapenem-resistance. Indian subcontinent was identified as the primary reservoir of this powerful metallo- $\beta$-lactamases (MBLs), but they rapidly emerged around the world with sporadic descriptions in Mediterranean and American countries [1, 2]. The blandM-like genes are usually found on mobile genetic elements that are horizontally transferred originating an extraordinary dissemination, creating a critical threat in healthcare institutions and patient safety $[1,2]$.

We describe, for the first time, an extensively drug resistant (XDR) K. pneumoniae clinical isolate, ST395, harboring blanDM-5-like, from a patient in Adjara hospital, Republic of Georgia.

During a survey in Adjara region, from april to december 2014, we detected a carbapenemresistant $K$. pneumoniae isolate from sputum, identified by ID32GN (bioMérieux, Marcyl'Étoile, France). The carbapenem-resistant clinical isolate was isolated from a patient admitted to a Central Hospital in Adjara region (Table 1).

Antimicrobial susceptibility testing was performed by disc diffusion methods according to the Clinical and Laboratory Standards Institute (CLSI) guidelines and tigecycline and colistin minimal inhibitory concentration (MIC) determination was performed by E-test (bioMérieux). Phenotypic methods for carbapenemase detection were performed, namely ethylenediaminetetraacetic acid (EDTA) inhibition according to the CLSI, blue-Carba [3], carbapenem inactivation method (CIM) [4] and inhibition studies using meropenem disc with various inhibitors (aminophenyl boronic acid/phenyl boronic acid, dipicolinic acid, cloxacilin and EDTA) according to the European Committee on Antimicrobial Susceptibility Testing 
(EUCAST) (http://www.eucast.org). Detection of relevant carbapenemase encoding genes

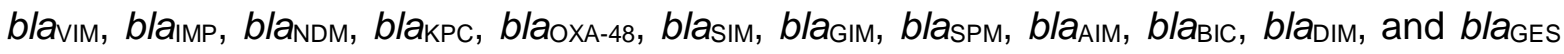
was done by PCR (table S1). Extended-spectrum beta-lactamase (ESBL) production was screened by the double-disk-synergy test (CTX) and confirmed by PCR, performed for detection of relevant $\beta$-lactamase genes: blatem, blaоXA-1, blasHv and blactX-м group 1, 2, 8, 9, 25 genes (table S1). Genes coding for resistance to non- $\beta$-lactam antibiotics namely quinolone resistance genes (qnrA, $\left.B, C, D, S, \operatorname{aac}\left(6^{\prime}\right)-l b-c r\right)$, tetracycline (tet $\left.A, B, C, E, G\right)$, sulfonamides (sul 1, 2, 3) and aminoglycosides (ant2, aph-III, aac3-II, aac(3)-IV) were also screened by PCR, according to the literature (table S1).

K. pneumoniae isolate was resistant to all carbapenems tested (namely imipenem, ertapenem, meropenem and doripenem), as well as to other $\beta$-lactams, including aztreonam, $\beta$-lactam-inhibitor association, and to non- $\beta$-lactam antibiotics (aminoglycosides, quinolones, tetracycline, chloramphenicol, trimethoprim-sulfamethoxazole) (Table 1). The selected XDR-carbapenem-resistant isolate is susceptible to colistin and tigecycline. Inhibition tests (using meropenem with various inhibitors), EDTA inhibition, Blue-Carba and $\mathrm{CIM}$, were positive for the carbapenem-resistant isolate, indicating the presence of a metalo-beta-lactamase (MBL) producer. This $K$. pneumoniae isolate is also an ESBL, CTXM-15 producer justifying resistance to aztreonam, also co-carried TEM, OXA-1 and SHV $\beta-$ lactamases and harbored the genes qnrD, qnrS, ant2, aph3-III and tetA (Table 1).

We detected bla NDM $_{\text {in }}$ the carbapenem-resistant isolate (strain 3) in sputum of an old patient (78 years) admitted to central hospital in Adjara. Amplicon sequencing identified NDM-5-like carbapenemase coding gene. Sequence type (ST) of $K$. pneumoniae was determined according to the scheme of multilocus sequence typing (MLST) available at the website (www.pasteur.fr/recherche/genopole/PF8/mlst/Kpneumoniae.html) and revealed that the strain belonged to sequence type 395 . ST395 has been reported in KPC-2 producing K. pneumoniae in China [5]. In this study we present the first description of NDMproducing K. pneumoniae ST395 worldwide.

This XDR clinical isolate, resistant to a wide variety of antimicrobial classes shows several resistance mechanisms leaving few therapeutic options, constitutes a risk for Adjara hospital in terms of outbreaks and patient safety and can contribute to the interregional 
dissemination in this country, by the circulation of patients in the healthcare network. During hospital stay, this patient with infection by NDM-5-like $K$. pneumoniae can maintain colonization with this XDR-Gram-negative, and this situation might contribute to the silent and rapid spread of NDM in the hospital setting and in healthy community, by the discharge of intestinally colonized patient.

In conclusion, this study represents the first report of NDM-type carbapenemase in Republic of Georgia. We need urgent and extensive surveillance in order to prevent and control the NDM dissemination in this country. Infection-control measures and active surveillance, including early detection of infected and/or intestinally colonized patients with carbapenemase producing Gram-negatives should be reinforced to minimize the hypothesis of dissemination of NDM in this hospital setting, as well as in geriatric healthcare institutions in community, as nursing homes and long-term care facilities.

\section{Acknowledgements}

Tea Koiava was supported by Shota Rustaveli National Science Foundation - PhD grant 2013 [Na40/01 06.12.2013].

We are grateful to Laurent Poirel for gently supplying Escherichia coli producing NDM control.

\section{Funding}

No specific funding was received for this study.

\section{Competing interests}

The authors declare no conflicts of interest.

\section{Ethical approval}

Not required. 


\section{References}

[1] Zmarlicka MT, Nailor MD, Nicolau DP. Impact of the New Delhi metallo-beta-lactamase on beta-lactam antibiotics. Infect Drug Resist 2015; 8: 297-309.

[2] Dortet L, Poirel L, Nordmann P. Worldwide dissemination of the NDMtype carbapenemases in Gram-negative bacteria. Biomed Res Int. 2014:249856.

[3] Pires J, Novais A, Peixe L. Blue-carba an easy biochemical test for detection of diverse carbapenemase producers directly from bacterial cultures. J Clin Microbiol 2013; 51(12):4281-3.

[4] Van der Zwaluw K, de Haan A, Pluister GN, Bootsma HJ, de Neeling AJ, Schouls LM. The carbapenem inactivation method (CIM), a simple and low-cost alternative for the Carba NP test to assess phenotypic carbapenemase activity in gram-negative rods. PLoS One, 2015; 10(3):e0123690.

[5] Wang LH, Wei DD, Wan LG, Yu Y, Deng Q, Liu Y. Diversity of the Genetic Environment of the blaKPC-2 Gene among Klebsiella pneumoniae clinical Isolates in a Chinese Hospital. Microb Drug Resist. 2016 Jan;22(1):15-21. 
Table 1 - Phenotypic and molecular characteristics of XDR-carbapenem-resistant $K$. pneumoniae isolate from Adjara hospital

\begin{tabular}{|c|c|c|c|c|c|c|c|c|c|c|c|c|c|c|c|}
\hline \multirow[b]{2}{*}{$\begin{array}{l}\text { Hospi } \\
\text { tal } \\
\text { code }\end{array}$} & \multirow[b]{2}{*}{$\begin{array}{l}\text { Isol } \\
\text { ate } \\
\text { no. }\end{array}$} & \multirow[b]{2}{*}{$\begin{array}{l}\text { Isolate } \\
\text { date }\end{array}$} & \multirow[b]{2}{*}{$\begin{array}{l}\mathrm{Ag} \\
\mathrm{e} / \\
\mathrm{Se} \\
\mathrm{x}^{\mathrm{a}}\end{array}$} & \multirow[b]{2}{*}{$\begin{array}{l}\text { Biolo } \\
\text { gic } \\
\text { produ } \\
\text { ct }\end{array}$} & \multicolumn{6}{|c|}{$\begin{array}{l}\text { Phenotypic cabapenemase detection } \\
\text { methods }\end{array}$} & \multirow[b]{2}{*}{$\begin{array}{l}\text { Carbapene } \\
\text { mases }\end{array}$} & \multirow[b]{2}{*}{ ESBL } & \multirow[b]{2}{*}{$\begin{array}{l}\text { Other } \beta- \\
\text { lactamase } \\
\quad s\end{array}$} & \multirow[b]{2}{*}{$\begin{array}{l}\text { Resistance to non } \beta- \\
\text { lactamic antibiotics }{ }^{h}\end{array}$} & \multirow[b]{2}{*}{$\begin{array}{l}\text { Resistance to non } \\
\beta \text {-lactamic } \\
\text { antibiotics } \\
\text { encoding genes }\end{array}$} \\
\hline & & & & & $\begin{array}{c}\text { EDTA } \\
\text { inhibiti } \\
\text { on b }\end{array}$ & $\begin{array}{l}\text { Blu } \\
\text { e- } \\
\text { Car } \\
\text { ba }\end{array}$ & $\underset{M^{d}}{\mathrm{Cl}}$ & $\begin{array}{l}\mathrm{ME} \\
\mathrm{R} / \mathrm{D} \\
\mathrm{PA}\end{array}$ & $\begin{array}{l}\mathrm{ME} \\
\mathrm{R} / \mathrm{P} \\
\mathrm{BA} \\
\mathrm{f}\end{array}$ & $\begin{array}{l}\mathrm{ME} \\
\mathrm{R} / \mathrm{C} \\
\mathrm{LX} \\
\mathrm{g}\end{array}$ & & & & & \\
\hline A & 3 & $\begin{array}{l}\text { April- } \\
2014\end{array}$ & $\begin{array}{l}78 / \\
M\end{array}$ & sputum & + & + & + & + & - & - & NDM & $\begin{array}{l}\text { CTX-M } \\
\text { group } 1\end{array}$ & $\begin{array}{l}\text { TEM, SHV, } \\
\text { OXA-1 }\end{array}$ & $\begin{array}{l}\text { GEN, TOB, AMK, NET, CIP, } \\
\text { LEV, TET, SXT, CHL }\end{array}$ & $\begin{array}{l}\text { qnrD, qnrS, ant2, aph3- } \\
\text { III, tetA }\end{array}$ \\
\hline
\end{tabular}

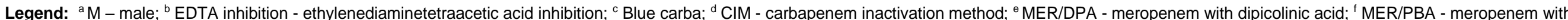

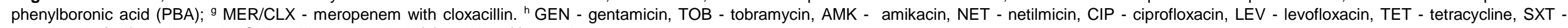
trimethoprim/sulfamethoxazole, $\mathrm{CHL}$ - chloramphenicol. (+) positive; (-) negative. 